\title{
Measurements of Np-237 incineration in ADS setup QUINTA
}

\author{
S. Kilim ${ }^{1}$, M. Bielewicz, E. Strugalska-Gola, M. Szuta \\ National Centre for Nuclear Research \\ ul. Andrzeja Soltana 7, 05-400 Otwock, Poland \\ E-mail: $\quad$ stanislaw.kilim@ncbj.gov.pl; marcin.bielewicz@ncbj.gov.pl; \\ elzbieta.strugalska-gola@ncbj.gov.pl; marcin.szutalncbj.gov.pl
}

W. I. Furman, S. Tyutyunnikov, J. Adam, L. Zavorka, J. Khushvaktov, Yu. Kish, V. M.

Tsoupko-Sitnikov, A. A. Solnyshkin, J. Vrzalova

Joint Institute for Nuclear Research

Joliot Curie str. 6, 141980 Dubna, Russia

E-mail: furmanenf.jinr.ru; tsi210647@yandex.ru; iadamejinr.ru; zavorka@jinr.ru; khushvaktov@mail.ru; kishyura@jinr.ru; vtsoupko@jinr.ru; solnejinr.ru; vrzalova@ujf.cas.cz

\section{V. Chilap}

Center of Physics and Technical Projects ,Atomenergomash“

Moscow 125130, Russsia

E-mail: chilapecftp-aem.ru

Np-237 samples were irradiated in spallation neutrons produced in ADS setup QUINTA. Three experiments were carried out. The accelerated beam consisted of deuteron ions of energy 2, 4 and 8 $\mathrm{GeV}$ respectively. The method was based on gamma-ray spectrometry measurement. During analysis of the spectra several fission products and one actinide were identified. Fission product activities gave the number of fissions. The actinide ( $\mathrm{Np}-238$ ), a result of neutron capture by $\mathrm{Np}-237$ gave the number of captures.

XXII International Baldin Seminar on High Energy Physics Problems

15-20 September 2014

JINR, Dubna, Russia

\section{${ }^{1}$ Speaker}




\section{Introduction}

The actinides is a name of a series of 15 chemical elements of atomic number from 89 (actinium) to 103 (lawrencium). The two of them - uranium and plutonium - called mayor actinides are basic components of the nuclear reactor fuel. Of the remaining the three - neptunium, americium and curium (called minor actinides) - are byproducts of energy production in reactor resulting in effect of parasitic neutron capture. About $10-20 \%$ of fissionable isotopes are transmuted in reactor into minor actinides. As they are long lived and in typical nuclear power reactor the parasitic neutron capture prevails, it is difficult to incinerate them. They accumulate. At present, approximately 2500 tons of spent fuel containing about 25 tons of plutonium and 3.5 tons of the "minor actinides" (MAs) neptunium, americium, and curium, as well as 3 tons of long-lived FPs (out of a total of about 100 tons of FPs) are produced annually in the European Union [1]. Sooner or later comes the time for mankind to face the problem of active actinides. Np-237 is a typical minor actinide. Fig. 1 shows its fission and neutron capture dependence on energy. It is seen that only for neutrons of energy above $1 \mathrm{MeV}$ the fission prevails the capture. QUINTA setup is a kind of ADS-type spallation neutron source made of natural uranium surrounded by lead shield. It is located in Dubna, Russia in Joint Institute for Nuclear Research. Np-237 samples were irradiated in it and resulting gamma activity was measured then. The main result of this work is fission to capture ratio for $\mathrm{Np}-237$.

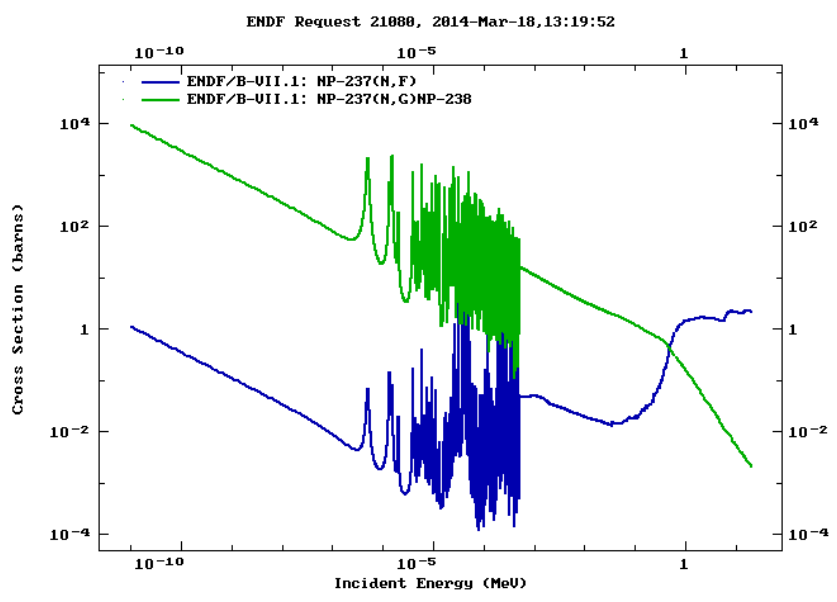

Figure 1. Np-237 neutron caused fission (dark blue) and capture (green) cross section dependence on energy [2].

\section{Experiment description}

Beams of deuterons provided by the NUCLOTRON Accelerator impinged on uranium assembly QUINTA. Spallation of uranium nuclei was initiated. The QUINTA setup is shown below - Fig. 2. More details on QUINTA can be found in [3]. Actinide samples were located in the "window" marked on red, seen on the right drawing. Beam run is shown on Fig. 3 and some more data in Table 1. 

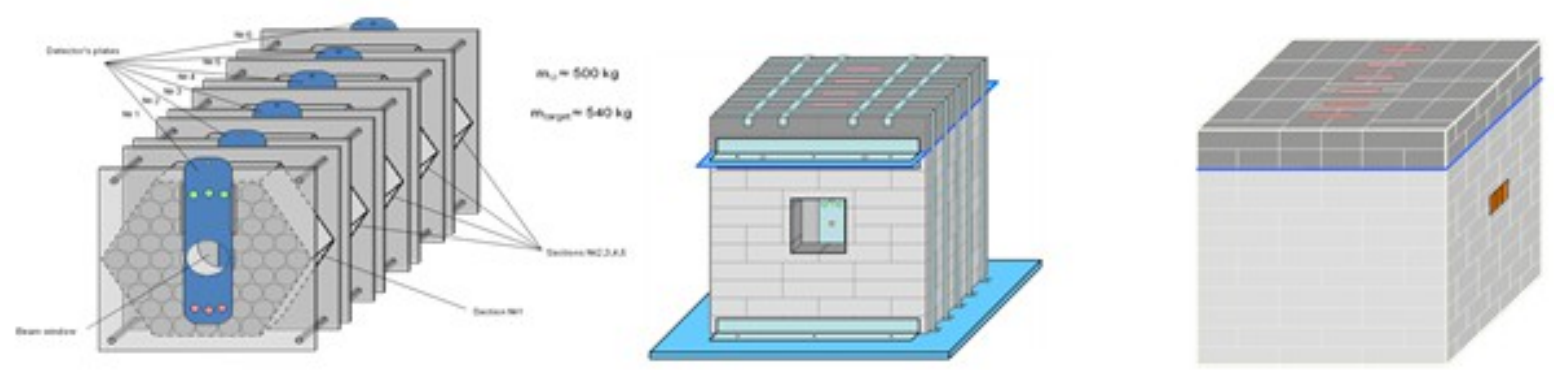

Figure 2. QUINTA setup view - internal core, front view and rear view.

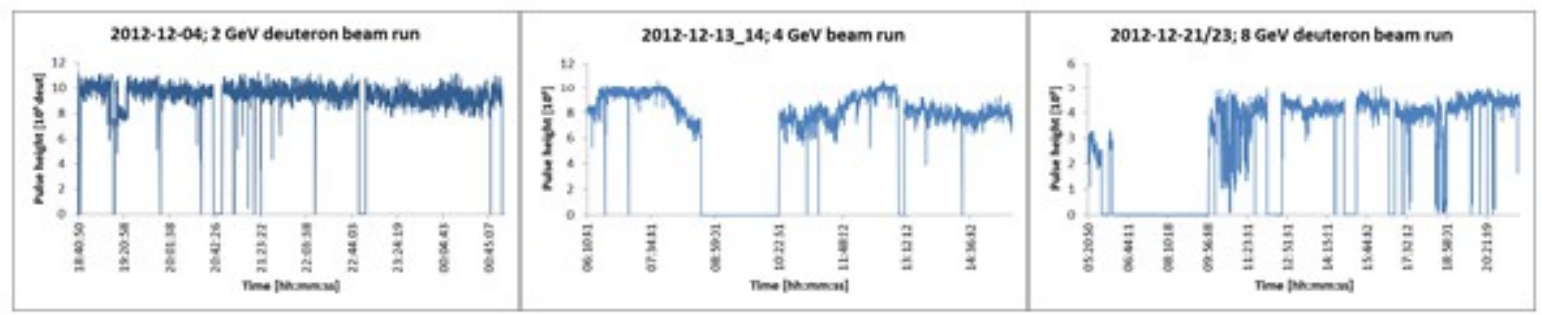

Figure 3. Deuteron beam run during 2, 4 and $8 \mathrm{GeV}$ energy experiments

Each Np-237 sample had cylinder form of $21 \mathrm{~mm}$ diameter encapsulated in U-shaped casing. The sample activity was measured tenfold at least at the CANBERRA GR1819 spectrometer. The spectroscopy filters made of $\mathrm{Pb}, \mathrm{Cd}$ and $\mathrm{Cu}$ were used to reduce $\mathrm{X}$ and low gamma activities.

Table 1. December 2012 experiments data [4]

$\begin{array}{llll}\text { Beam energy } & \mathbf{2 ~ G e V} & \mathbf{4 ~ G e V} & \mathbf{8 ~ G e V} \\ \text { Date } & 04 \mathrm{Dec} 2012 & 13 \mathrm{Dec} 2012 & 22 \mathrm{Dec} 2012 \\ \text { Irradiation time }(\mathbf{h}) & 6.27 & 9.35 & 16.17 \\ \text { Total number of deuterons }\left(\mathbf{1 0}^{\mathbf{1 3}}\right) & 3.052(9) & 3.569(15) & 1.390(8)\end{array}$

\section{Experimental data work-out details}

Gamma spectra were analyzed with DEIMOS program [5]. Identified peak area was corrected then for cooling time, irradiation time, detector efficiency and fission product yield to get $\mathrm{Np}-237$ fission rate $I_{f \gamma}$.

$$
\begin{aligned}
I_{f \gamma} & =\frac{W_{1}}{W_{2}} \cdot C_{I H} \\
W_{1} & =\frac{100 \cdot S_{\gamma}}{\varepsilon_{p} \cdot I_{\gamma}} \cdot \frac{1}{\left(1-e^{-\lambda t_{\text {real }}}\right)} \cdot \frac{t_{\text {real }}}{t_{\text {live }}} \\
W_{2} & =\frac{m \cdot \phi \cdot \gamma_{f} \cdot\left(1-e^{-\lambda \cdot t_{\text {ir }}}\right)}{100 \cdot \lambda \cdot t_{\text {ir }}} \cdot e^{-\lambda t_{+}}
\end{aligned}
$$

$I_{f y}$ - actinide fission rate, per deuteron and per gram

$\gamma$-gamma line index $f$ - reaction index $(f=$ fission $)$

$S_{\gamma}$ - gamma peak area

$\gamma_{f}-$ isotope production yield [\%] 
$m$ - activation sample mass [g]

$\gamma_{p}$ - gamma spectrometer efficiency
$I_{\gamma}$ - gamma line intensity [\%]
$\phi$ - deuteron integral number
$\lambda$ - isotope decay constant
$t_{+}-$cooling time
$t_{i r}$ - irradiation time
$t_{\text {real }}$ - real time of measurement
$t_{\text {live }}-$ live time of measuremet
$C_{I H}-$ correction for irradiation history

Formula for neutron capture rate was very similar except the $\gamma_{f}$ correction omitted. 
Some decaying isotopes are produced in two ways - directly from Np-237 fission and indirectly, as a result of other the fission products decay chain. Te-132 $\rightarrow$ I-132 decay chain is a very illustrative example of this case [6].

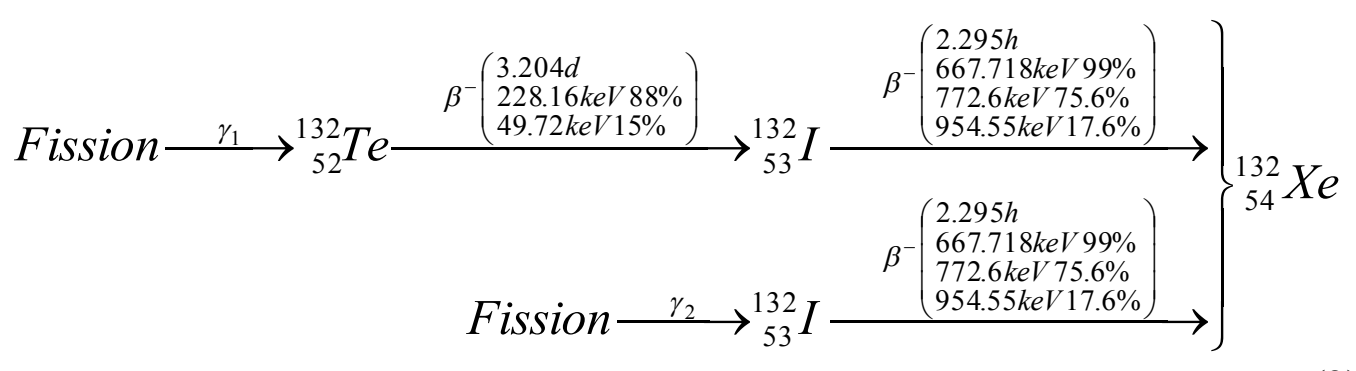

In fact Te-132 isotope can have several predecessors but their life time is so short that their contribution can be included into $\gamma_{1}$ making it a cumulative fission yield while $\gamma_{2}$ is an individual one. Based on [7] fission yield data one has $\gamma_{1}=3.98 \%$ and $\gamma_{2}=0.407 \%$.

The above decay chain specificity is that I-132 half life time $(2.29 \mathrm{~h})$ is much shorter than the Te-132 one (3.204d). It causes the I-132 lines $(667.71,772.6$ and $954.55 \mathrm{keV})$ to decay not according to $2.295 \mathrm{~h}$ but $3.204 \mathrm{~d}$ half life time. Therefore $\mathrm{W}_{2}$ expression in (1) gets for I-132 lines changed to:

$$
W_{2}=m \cdot \phi \cdot\left(\frac{\gamma_{1} \cdot\left(1-e^{-\lambda_{1} \cdot t_{i r}}\right)}{100 \cdot \lambda_{1} \cdot t_{i r}} \cdot e^{-\lambda_{1} t_{+}}+\frac{\gamma_{2} \cdot\left(1-e^{-\lambda_{2} \cdot t_{i r}}\right)}{100 \cdot \lambda_{2} \cdot t_{i r}} \cdot e^{-\lambda_{2} t_{+}}\right)
$$

The spectrometer efficiency curve was based on Co-60, Ba-133, Cs-137, Eu-152 and Th-228 calibration sources activity measurements. The detector efficiency $\left(\varepsilon_{p}\right)$ curve is shown on Fig. 4.

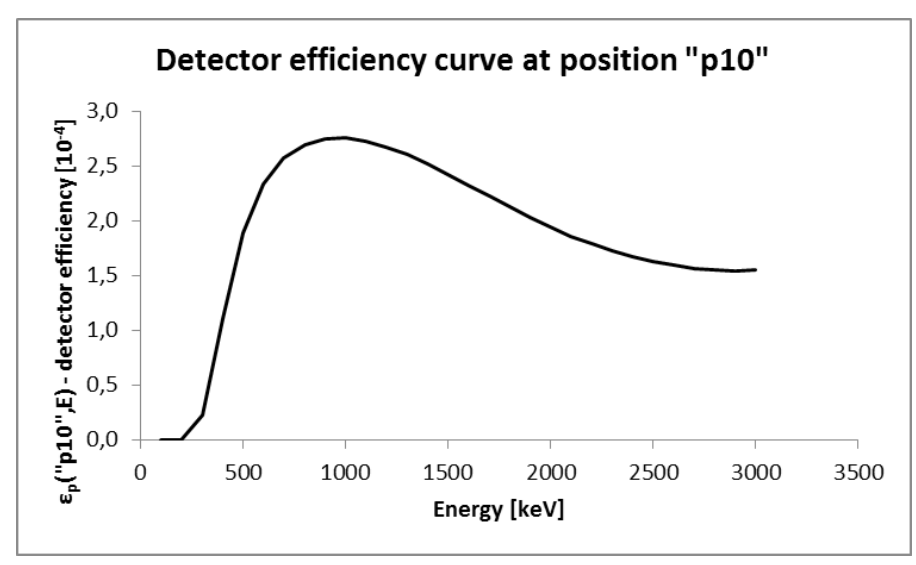

Figure 4. HPGe detector efficiency dependence on energy 
Looking at Fig. 3 one can see beam run or irradiation history. During experiment $2(4 \mathrm{GeV})$ and $3(8 \mathrm{GeV})$ there was quite a big time interval with no beam. The deviation of real beam run from the "flat" one was corrected by formula:

$$
C_{I H}=\left(\sum_{i=1}^{i r} \varphi_{i} e^{-\lambda\left(t_{i r}-t_{i}\right)}\right) \frac{\lambda t_{i r}}{\phi\left(1-e^{-\lambda t_{i r}}\right)}
$$

Here $\varphi_{i}$ means number of deuterons in $i$-th beam shot (pulse), $\phi$ total number of deuterons, $i$ numbers the beam shots. The correction equals 1 for experiment $1(2 \mathrm{GeV})$, mostly 1 but 1.02 for I-135 and 1.07 for Sr-92 for experiment $2(4 \mathrm{GeV})$ and much bigger for experiment 3 (8 $\mathrm{GeV}$ ) where it reaches 1.21 and 1.43 for I-135 and Sr-93 respectively.

\section{Results}

There are two sources of gamma quanta - fission product (FP) activity and neutron capture product $(\mathrm{CP})$ activity. The identified products and their data are shown in Table 2.

Table 2. Sample Np-237 identified gamma lines and their data

\begin{tabular}{|c|c|c|c|c|c|}
\hline E-gamma & Isotope & Source & $\mathrm{T} 1 / 2$ & $\begin{array}{l}\text { Fission yield } \\
\text { [\%] [7] }\end{array}$ & $\begin{array}{c}\text { I-gamma } \\
\text { [\%] [6] }\end{array}$ \\
\hline 529.87 & $133 \mid$ & FP & $20.87 \mathrm{~h}$ & 4,45 & 87 \\
\hline 657.94 & ${ }^{97} \mathrm{Zr}->{ }^{97} \mathrm{Nb}^{*}$ & FP & $\begin{array}{c}16.744 \\
h\end{array}$ & 5,38 & 98,23 \\
\hline 667.71 & ${ }^{132} \mathrm{Te}->\left.^{132}\right|^{* *}$ & FP & $3.26 \mathrm{~d}$ & 4,39 & 98,7 \\
\hline 743.36 & ${ }^{97} \mathrm{Zr}$ & FP & $\begin{array}{c}16.744 \\
h\end{array}$ & 5,35 & 93,6 \\
\hline 772.6 & ${ }^{132} \mathrm{Te}->{ }^{132} \mid * *$ & FP & $3.26 \mathrm{~d}$ & 4,39 & 75,6 \\
\hline 954.55 & ${ }^{132} \mathrm{Te}->{ }^{132} \mid * *$ & FP & $3.26 \mathrm{~d}$ & 4,39 & 17,6 \\
\hline 1131.51 & $135 \mid$ & FP & $6.57 \mathrm{~h}$ & 4,16 & 22,6 \\
\hline 1260.41 & 135 & FP & $6.57 \mathrm{~h}$ & 4,16 & 28,7 \\
\hline 923.98 & ${ }^{238} \mathrm{~Np}$ & $\mathrm{CP}$ & $2.117 d$ & N/A & 2,869 \\
\hline 962.77 & ${ }^{238} \mathrm{~Np}$ & $\mathrm{CP}$ & $2.117 d$ & N/A & 0,702 \\
\hline 984.45 & ${ }^{238} \mathrm{~Np}$ & $\mathrm{CP}$ & $2.117 d$ & N/A & 27,8 \\
\hline 1025.87 & ${ }^{238} \mathrm{~Np}$ & $\mathrm{CP}$ & $2.117 d$ & N/A & 9,65 \\
\hline 1028.54 & ${ }^{238} \mathrm{~Np}$ & $\mathrm{CP}$ & $2.117 d$ & N/A & 20,38 \\
\hline
\end{tabular}

$\mathrm{FP}$ - fission product. $\mathrm{CP}$ - neutron capture product.

*Line $657.94 \mathrm{keV}$ stems in fact from Nb-97 beta decay, but its quantity is modified by $\mathrm{Zr}-97$ decay rate $[6,7],(16.8 \mathrm{~h})$.

$\begin{array}{llll}\text { Isotope } & \mathrm{T} 1 / 2 & \text { Y-individual [\%] } & \text { Y-cum [\%] } \\ { }^{97} \mathrm{Y} & 3.76 \mathrm{~s} & 3.22 & 4.25 \\ { }^{97} \mathrm{Zr} & 16.8 \mathrm{~h} & 1.09 & 5.35 \\ { }^{97} \mathrm{Nb}-\mathrm{m} & 58.1 \mathrm{~s} & 3.83 \mathrm{E}-03 & 5.03 \\ { }^{97} \mathrm{Nb} & 1.23 \mathrm{~h} & 3.10 \mathrm{E}-02 & 5.38\end{array}$

**Lines $667.71,772.6$ and $954.55 \mathrm{keV}$ stem from I-132 but their activities are modified by Te132 decay rate $[6,7],(3.26 \mathrm{~d})$.

$\begin{array}{llll}\text { Isotope } & \mathrm{T} 1 / 2 & \text { Y-individual [\%] } & \text { Y-cum [\%] } \\ { }^{132} \mathrm{Sb} & 4.2 \mathrm{~m} & 5.59 \mathrm{E}-01 & 6.00 \mathrm{E}-01 \\ { }^{132} \mathrm{Te} & 3.26 \mathrm{~d} & 2.47 & 3.98 \\ { }^{132} \mathrm{I} & 2.28 \mathrm{~h} & 4.07 \mathrm{E}-01 & 4.39 \\ { }^{132} \mathrm{Xe} & \text { stable } & 7.10 \mathrm{E}-03 & 4.40\end{array}$


The results of measurements are shown on Fig. 5 grouped by experiment (rows) and fission, capture (columns). No data were rejected. They were treated as equivalent members of the same population and their average value is an arithmetical mean while the error, $\sigma$ is a standard deviation of the population. The average values are shown on Fig. 6 and Table 3, while fission to capture ratio on Fig. 7 and Table 4.

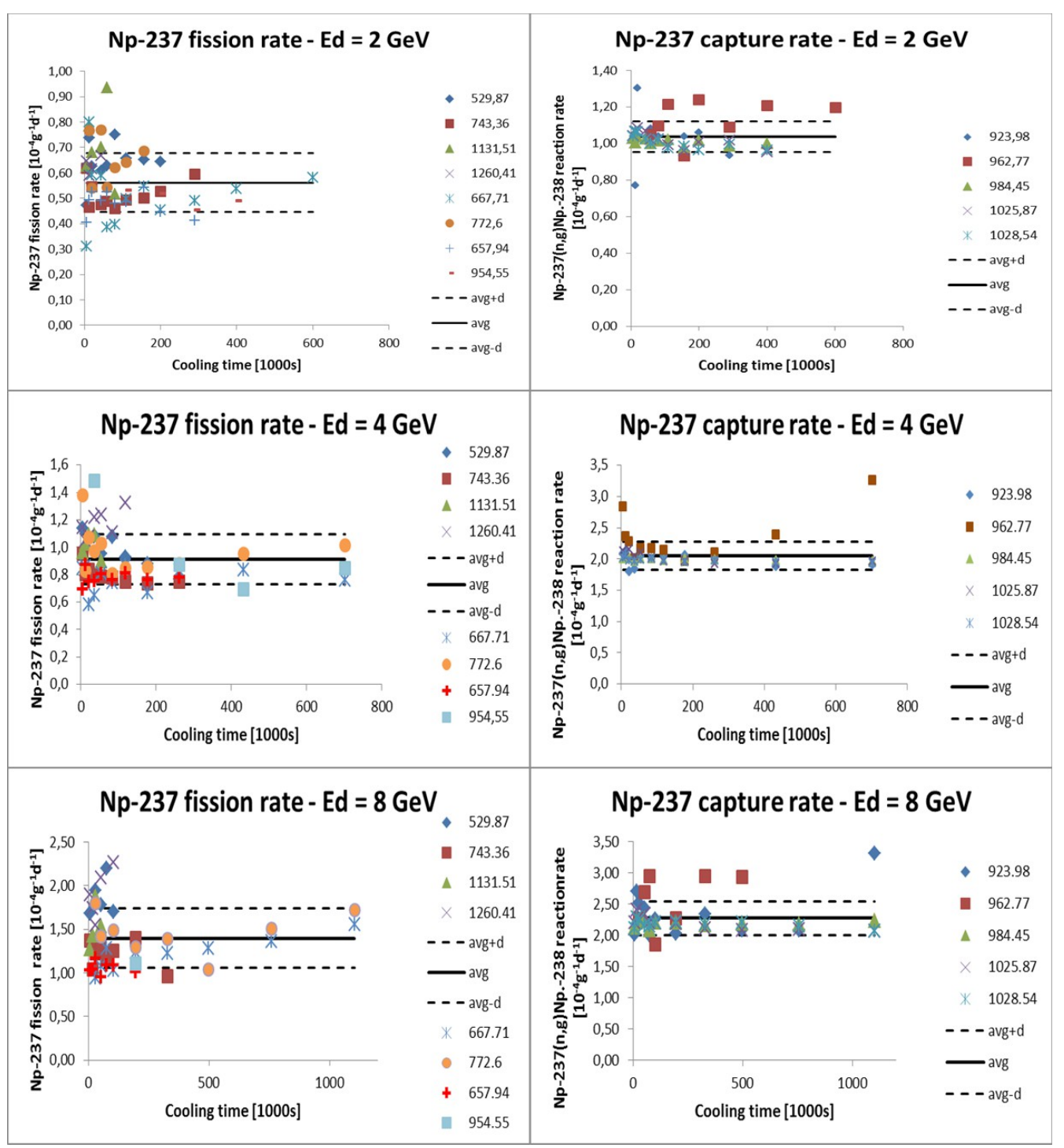

Figure 5. Np-237 fission and capture rate based on identified gamma lines for beam deuteron energies 2 , 4 and $8 \mathrm{GeV}$. Solid and dashed lines show $\pm \sigma$ (standard deviation of population) range. 


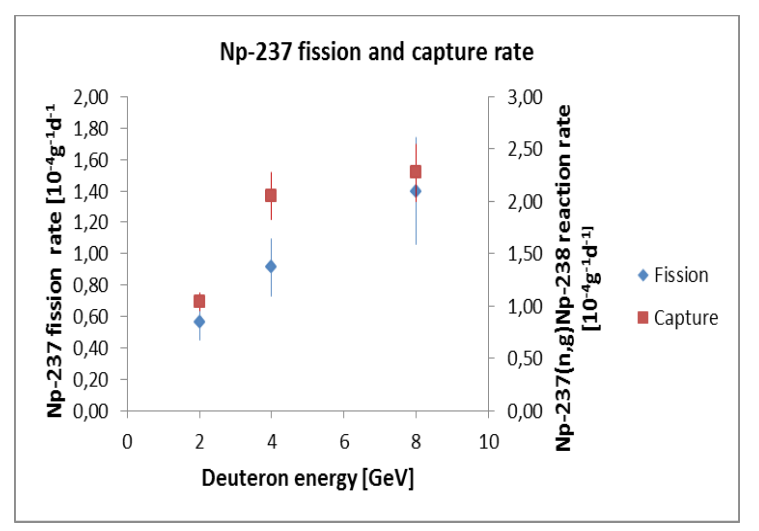

Figure 6. Np-237 average fission and capture rate per gram and per 1 deuteron dependence on energy

Table 3. Np-237 fission and capture rate per sample gram and per 1 deuteron

$\begin{array}{cllcccc}\begin{array}{c}\text { Beam } \\ \text { deuteron } \\ \text { energy } \\ {[\mathrm{GeV}]}\end{array} & \begin{array}{c}\text { Fission rate } \\ {\left[\mathbf{1 0}^{-4} \mathbf{g}^{-1} \mathbf{d}^{-1}\right]}\end{array} & \begin{array}{c}\text { Standard } \\ \text { deviation } \\ {\left[\mathbf{1 0}^{-4} \mathbf{g}^{-1} \mathbf{d}^{-1}\right]}\end{array} & \begin{array}{c}\text { Standard } \\ \text { deviation } \\ {[\%]}\end{array} & \begin{array}{c}\text { Capture } \\ \text { rate } \\ {\left[10^{-4} \mathbf{g}^{-1} \mathbf{d}^{-1}\right]}\end{array} & \begin{array}{c}\text { Standard } \\ \text { deviation } \\ {\left[\mathbf{1 0}^{-4} \mathbf{g}^{-1} \mathbf{d}^{-1}\right]}\end{array} & \begin{array}{c}\text { Standard } \\ \text { deviation } \\ {[\%]}\end{array} \\ 2 & 0.562 & 0.115 & 20.41 & 1.04 & 0.084 & 8.1 \\ 4 & 0.913 & 0.181 & 19.84 & 2.05 & 0.226 & 11.04 \\ 8 & 1.40 & 0.339 & 24.28 & 2.27 & 0.270 & 11.89\end{array}$

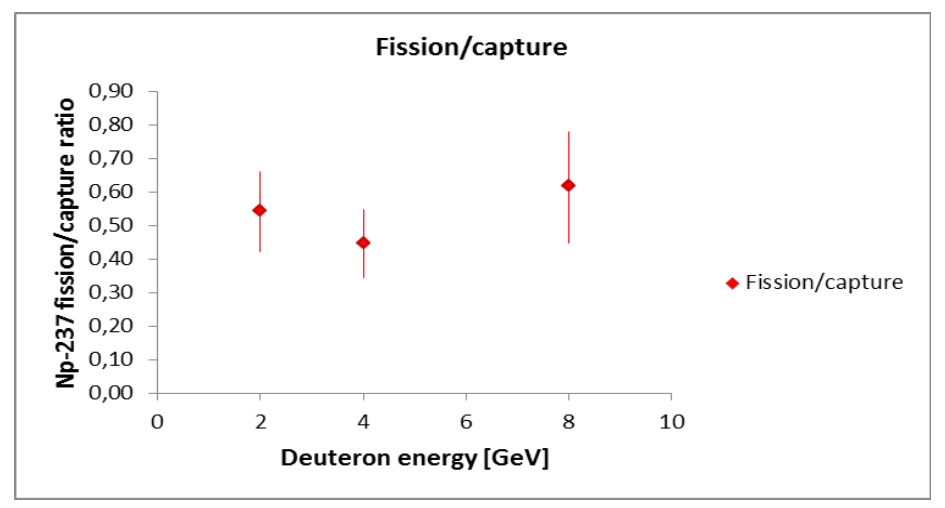

Figure 7. Np-237 fission to capture ratio dependence on beam deuteron energy

Table 4. Np-237 fission/Capture ratio dependence on beam deuteron energy

$\begin{array}{ccccccc}\begin{array}{c}\text { Beam } \\ \text { deuteron } \\ \text { energy }\end{array} & \begin{array}{c}\text { Fission/Capture } \\ \text { ratio }\end{array} & \begin{array}{c}\text { Standard } \\ \text { deviation }\end{array} & \begin{array}{c}\text { Standard } \\ \text { deviation } \\ {[\%]}\end{array} & \begin{array}{c}\text { Fission/absorption } \\ \text { ratio }\end{array} & \begin{array}{c}\text { Standard } \\ \text { deviation }\end{array} & \begin{array}{c}\text { Standard } \\ \text { deviation } \\ {[\%]}\end{array} \\ 2 & 0.541 & 0.119 & 21.96 & 0.35 & 0.08 & 22.26 \\ 4 & 0.445 & 0.101 & 22.70 & 0.31 & 0.07 & 22.12 \\ 8 & 0.615 & 0.166 & 27.03 & 0.38 & 0.10 & 27.00\end{array}$

Based on these data fission/capture seems not to depend on energy, what suggests the neutron 
spectrum not to depend on energy as well. To compare these data with literature [1] - Fig. 8 fission to absorption ratio is given in Table 4 as well. The comparison says the QUINTA setup to be about 1.4 times more effective in Np-237 incineration than Sodium-cooled Fast Reactor (SFR). Nevertheless the neutron capture is still about two times higher than the fission (incineration) what means the trans-Np-237 actinides cumulate.

\section{Conclusions}

The fission/capture ratio seems to be constant in the explored deuteron energy range ( $2-8$ $\mathrm{GeV}$ ), of order 0.53 while fission to absorption ratio is of order 0.35 .

Comparison of the determined fission to absorption ratio with literature data says the QUINTA setup to be about 1.4 times more effective in Np-237 incineration than Sodium-cooled Fast Reactor (SFR). Nevertheless the incineration does not prevent the trans-Np-237 actinides accumulation.

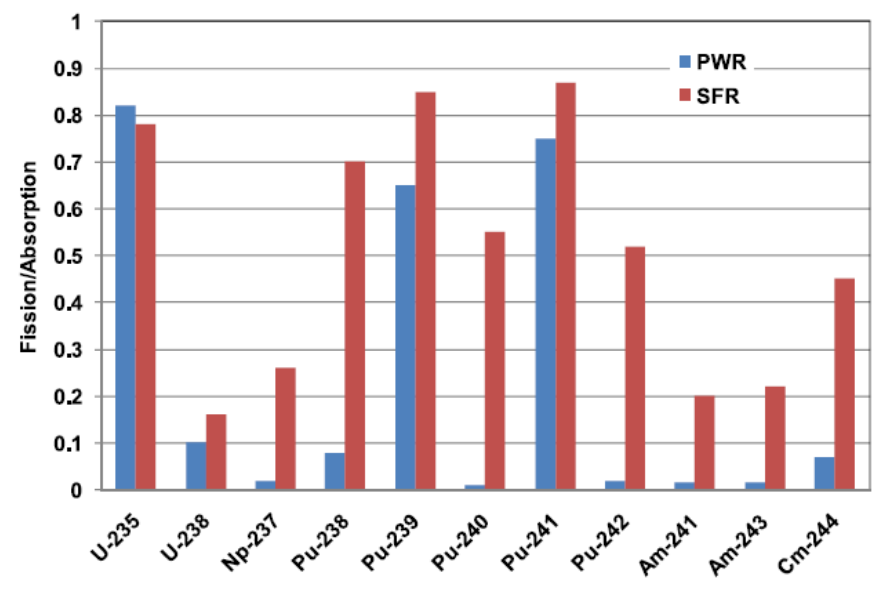

Figure 8. Actinides fission to absorption ratio for PWR and SFR [1]

\section{Acknowledgments}

The authors would like to thank the staff of the Nuclotron accelerator of the Joint Institute for Nuclear Research, Dubna for providing access to the research facilities used in these experiments.

This work was carried out as part of the Strategic Project "Safe Nuclear Power Engineering Development Technologies" supported by The National Centre for Research and Development, Poland.

\section{References}

[1] M. Salvatores, G. Palmiotti; Radioactive waste partitioning and transmutation within advanced fuel cycles: Achievements and challenges; Progress in Particle and Nuclear Physics 66 (2011) 144-166.

[2] Evaluated Nuclear Data File (ENDF); https://www-nds.iaea.org/exfor/endf.htm

[3] W. Furman et al.; Recent results of the study of ADS with $500 \mathrm{~kg}$ natural uranium target assembly QUINTA irradiated by deuterons with energies from 1 to $8 \mathrm{GeV}$ at JINR NUCLOTRON; PoS(Baldin ISHEPP XXI)086. 
[4] M. Suchopár et al.; The intensity of the deuteron beams on Kvinta targets (experiment December 2012) - preliminary results from the Řež group; KVINTA project internal communication.

[5] Frána J.; Program DEIMOS32 for Gamma-Ray Spectra Evaluation, J. Rad. Nucl. Chem., V. 257, No. 3 P. (2003) 583-587.

[6] TABLE OF ISOTOPES, 8E

[7] http://ie.lbl.gov/fission.html http://ie.lbl.gov/fission/237nph.txt 